\title{
Reação de acessos de jurubeba à murcha bacteriana para uso como porta-enxerto em tomateiro
}

\author{
Carlos A Lopes; José L Mendonça \\ Embrapa Hortaliças, Brasília-DF, Brasil; carlos.lopes@embrapa.br; jose.mendonca@embrapa.br
}

\begin{abstract}
RESUMO
A murcha bacteriana, causada pelo patógeno de solo Ralstonia solanacearum, é uma séria ameaça à produção de tomate em cultivos sujeitos a alta temperatura e alta umidade. O controle dessa doença é muito difícil e requer várias estratégias, entre as quais a enxertia tem ganhado notoriedade nos últimos anos, em especial após o lançamento de híbridos de porta-enxertos de tomateiro desenvolvidos especiamente para esta finalidade. Embora promovam considerável proteção contra a murcha bacteriana, os porta-enxertos de tomateiro podem se infectar em situações muito favoráveis à doença, tais como: alta população do patógeno, alta temperatura e umidade e presença de isolado muito agressivo. O objetivo desse trabalho foi avaliar duas espécies de jurubeba na busca de alto grau de resistência à murcha bacteriana. Foram avaliados, em experimentos conduzidos em casa de vegetação em Brasília-DF, 26 acessos de cada uma das espécies Solanum scuticum e Solanum stramonifolium, conhecidas no Brasil com o nome genérico de jurubeba. Em uma primeira etapa, os acessos foram inoculados com um isolado de $R$. solanacearum e, posteriormente, os mais resistentes desafiados com três isolados altamente virulentos pertencentes a diferentes biovares/filotipos. Acessos de $S$. scuticum apresentaram variação quanto ao grau de resistência, com 15 dos 26 acessos mostrando reação do tipo imunidade à doença, mesmo aos isolados mais virulentos. Não houve correlação significativa entre grau de resistência e local de coleta dos acessos. Os acessos de S. stramonifolium, diferentemente de S. scuticum, mostraram reação uniforme, e todos foram altamente resistentes à doença. As duas espécies de jurubeba avaliadas, portanto, contêm acessos com alto nível de resistência à murcha bacteriana e seu uso como porta-enxerto é viável para o controle da doença, desde que seja ajustada a combinação correta enxerto versus porta-enxerto e garanta adequada compatibilidade.
\end{abstract}

Palavras-chave: Ralstonia solanacearum, Solanum scuticum, Solanum stramonifolium, Solanum lycopersicum, enxertia.

\begin{abstract}
Reaction of accessions of two species of "jurubeba" as rootstocks to protect tomato plants against bacterial wilt

Bacterial wilt, induced by the soil pathogen Ralstonia solanacearum, is a serious tomato disease in tropical countries in areas subject to high temperatures and high humidity. Disease control is very difficult and requires a set of management measures, among them grafting, which has become more popular after the release of a set of commercial tomato resistant rootstocks. Although protection conferred by these rootstocks has been effective in many locations, it is not enough under situations very conducive to bacterial wilt, such as high populations of the pathogen in the soil, high temperature, high soil humidity and presence of an aggressive strain of the pathogen. The objective of this work was to assess the potential of accessions of two Solanum species known as "jurubeba" in Brasil, as rootstocks to protect tomato plants against bacterial wilt through grafting. In experiments carried out under greenhouse conditions in Brasilia, 26 accessions of each Solanum scuticum and S. stramonifolium were tested. In a first phase, the set of accessions were challenged with one isolate of $R$. solanacearum previously known by its high virulence to solanaceous crops. In a second phase, three representative resistant accessions were challenged with three isolates of the pathogen also previously chosen for their high virulence to tomato and sweet pepper and distinct biovar/phylotype. Accessions of $S$. scuticum reacted differently to the pathogen's isolates, but 15 out of 26 accessions presented an immune-like resistance to all bacterial isolates. No correlation was observed between resistance and origin of the accessions. S. stramonifolium accessions, differently from $S$. scuticum, were all resistant to the bacterial isolates. The two species of "jurubeba", therefore, contain accessions that are higly resistant to a range of virulent isolates of $R$. solanacearum. Their use as rootstocks to protect tomato against bacterial wilt is viable, but further research is needed to solve eventual problems related to the rootstock-scion compatibility.
\end{abstract}

Keywords: Ralstonia solanacearum, Solanum scuticum, Solanum stramonifolium, Solanum lycopersicum, grafting.

(Recebido para publicação em 5 de fevereiro de 2015; aceito em 28 de janeiro de 2016)

(Received on February 5, 2015; accepted on January 28, 2016)

A s primeiras notícias de uso da enxertia no cultivo de hortaliças no Brasil datam da década de 1950 na Região Norte, onde imigrantes japoneses estabelecidos no estado do Pará enxertavam tomateiro em 'jurubeba juna' (Solanum toxicarium, sin. S. stramonifolium), nativa da Região. Essa era a única alternativa para controlar a murcha bacteriana ou murchadeira, causada por Ralstonia solanacearum, endêmica na Região (Galli, 1980). A ocorrência de outros problemas fitossanitários na lavoura e a escassez de mão de obra para a realização da enxertia 
levaram os produtores a abandonar a tomaticultura e concentrar seus esforços em outros cultivos, em especial na produção de pimenta do reino, espécie muito bem adaptada à região.

Com o advento do cultivo protegido e sua expansão nas Regiões $\mathrm{Sul}$ e $\mathrm{Su}-$ deste, o problema causado pela murcha bacteriana também se expandiu. Se na Região Norte a população do patógeno naturalmente presente nos solos aumentava rapidamente face às condições climáticas favoráveis, em outras regiões o aumento gradativo dessa população no solo se deveu ao plantio sucessivo desta hortaliça na mesma área. Além disso, temperaturas mais altas dentro de estufas, muitas vezes com o uso de "mulch" preto, favorecem a multiplicação da bactéria e, consequentemente, a rápida evolução da doença.

A dificuldade de controle dos patógenos de plantas associados ao solo, principalmente em cultivo protegido, foi agravada após o banimento do brometo de metila, face às suas implicações na destruição da camada de ozônio. Com isso, surgiu a oportunidade de a enxertia ser reavaliada como tecnologia no sistema produtivo do tomate de mesa, dentro de um novo cenário que envolve: carência de alternativa de controle de alguns patógenos habitantes do solo; quebra da resistência pelo aparecimento de novas variantes dos patógenos; aumento significativo do cultivo protegido, favorecendo o incremento da população de patógenos de solo pelo plantio sucessivo da mesma espécie; predominância do plantio de híbridos, que justifica o aumento do custo da muda pelo custo da mão de obra para a enxertia; surgimento das presilhas de fixação do enxerto, que substituem as fitas, de colocação trabalhosa e possibilidade da mecanização do processo de enxertia, inclusive pelo uso de nanotecnologia, como robôs. Com isso, duas possibilidades se abrem: viabilizar o plantio em estufas contaminadas e exploração da cultura do tomateiro em regiões muito vulneráveis ao ataque da murcha bacteriana, como as Regiões Norte e Nordeste.

A técnica da enxertia apresenta grande potencial, pois alguns porta-enxertos, além de resistência a doenças, têm maior capacidade de absorção de água e nu- trientes do solo. O potencial de algumas solanáceas nativas tem sido explorado para algumas combinações para a produção de tomate visando resistência a doenças (Santos, 2003; Pinheiro et al., 2011). No caso do tomateiro, deve ser ressaltado que porta-enxertos ou eventuais cultivares com resistência à murcha bacteriana podem ser desprovidas de alto grau de resistência e estariam sujeitas ao ataque de estirpes do patógeno que quebram, total ou parcialmente, a resistência, sobretudo sob condições de alta temperatura e umidade do solo (Lopes et al., 2015; Wicker et al., 2007).

Visando obter porta-enxertos com alto grau de resistência a várias doenças de solo, a Embrapa Hortaliças vem avaliando genótipos de espécies nativas de Solanum. Estudos preliminares com o objetivo de avaliar a resistência à murcha bacteriana em acessos de Solanum stramonifolium, S. scuticum, S. paniculatum, S. subinerme e $S$. macrocarpum, da coleção de trabalho de Solanum da Embrapa Hortaliças, indicaram que acessos das quatro primeiras espécies se comportaram como resistentes e o da última como suscetível (Mendonça et al. 2009a; 2009b).

O objetivo deste trabalho foi avaliar um conjunto de acessos de Solanum scuticum e S. stramonifolium para resistência à murcha bacteriana, visando a obter informações a respeito de seu uso como porta-enxertos para proteger plantas de tomateiro da murcha bacteriana.

\section{MATERIAL E MÉTODOS}

\section{Avaliação de acessos de $S$. scuticum}

Nesse experimento, foram avaliados 26 acessos de $S$. scuticum coletados em diferentes regiões do Brasil e mantidos pela Embrapa Hortaliças (Tabela 1). O trabalho foi realizado em casa de vegetação, em 2012, na Embrapa Hortaliças, Brasília-DF. Sementes dos acessos foram semeadas em bandejas de isopor de 128 células contendo substrato comercial Bioplant ${ }^{\mathrm{R}}$. As mudas, aos 57 dias após a semeadura, foram inoculadas pela pulverização de suas raízes expostas pela retirada dos blocos das bandejas (cerca de $5 \mathrm{~mL} /$ planta). $\mathrm{Na}$ inoculação, foi usado o isolado CNPH RS 476, pertencente à R1Bv3 de $R$. solanacearum, cuja virulência à jurubeba havia sido previamente comprovada. $\mathrm{O}$ inóculo, na concentração de $10^{8} \mathrm{ufc} / \mathrm{mL}$, foi preparado riscando-se células mantidas em tubos com água, da coleção de bactérias da Embrapa Hortaliças, em placas de Petri contendo meio de Kelman (sem tetrazólio) (Kelman, 1954). As placas foram mantidas em BOD a $28^{\circ} \mathrm{C}$ por 48 horas, após as quais as colônias foram coletadas e diluidas em água estéril até a concentração desejada.

As mudas inoculadas foram mantidas em casa de vegetação $\left(20-42^{\circ} \mathrm{C}\right)$, com aquecimento noturno para evitar escapes, comuns se temperaturas abaixo de $19^{\circ} \mathrm{C}$ ocorrerem com frequência nos primeiros dias após a inoculação. As plantas inoculadas foram distribuídas em bancadas da casa de vegetação em desenho inteiramente casualizado com parcelas de três vasos com capacidade de 1,5 L com duas plantas, em duas repetições. Concomitantemente, para conferir a virulência do isolados, mudas de tomate suscetível 'San Vito', semeadas 30 dias após a semeadura da jurubeba, foram inoculadas da mesma maneira. A avaliação nesta primeira etapa foi feita pela incidência da doença, calculando-se a porcentagem de plantas murchas 15 dias após a inoculação. As médias dos tratamentos foram comparadas pelo teste de Tukey $(0,05)$.

\section{Avaliação de acessos especiais de S. scuticum}

Tendo como base o resultado do experimento 1, que mostrou grande diferença do grau de resistência entre os 26 acessos quando desafiados com um isolado de $R$. solanacearum, foram escolhidos três acessos resistentes (CNPH 62, CNPH 77, CNPH 78) e três suscetíveis (CNPH 69, CNPH 74, CNPH 87) à murcha bacteriana (Tabelas 1 e 2). Diferentemente do ensaio anterior, esses acessos foram desafiados com três isolados de $R$. solanacearum de diferentes biovares: RS 489 (R1Bv1), RS 488 (R1Bv2T) e RS 476 (R1Bv3). As mudas de jurubeba e de tomate, usado como testemunha suscetível e indicador da virulência dos isolados bacterianos, bem como o inóculo, foram preparados da mesma forma do experimento 1 , 
exceto a concentração da bactéria que foi padronizada com $5 \times 10^{7} \mathrm{ufc} / \mathrm{mL}$. O delineamento experimental foi inteiramente casualisado, face à uniformidade ambiental na casa de vegetação, em fatorial 3x6 (3 isolados x 6 acessos). A parcela experimental foi dois vasos de 1,5 L, cada um contendo duas plantas, em três repetições. A doença foi avaliada 15 dias após a inoculação por meio de uma escala de notas de 1 a 4, modificada de Winstead \& Kelman (1952), sendo: $1=$ planta sem sintoma; $2=$ uma folha até metade da planta murcha; $3=$ mais da metade até a planta toda murcha e $4=$ planta morta. Esta escala de severidade foi usada por oferecer melhor precisão na diferenciação entre genótipos.

Avaliação de acessos de Solanum stramonifolium

Neste experimento, foram avaliados 26 acessos de $S$. stramonifolium do banco de germoplasma da Embrapa Hortaliças (Tabela 3). Os procedimentos de produção de mudas e a inoculação foram similares aos descritos para S. scuticum, exceto pela idade das mudas de 54 dias após a semeadura e concentração de inóculo de $10^{8} \mathrm{ufc} / \mathrm{mL}$ do isolado $\mathrm{RS}$ 476 (R1Bv3) neste ensaio. As condições de pós-inoculação em casa de vegetação foram as mesmas do ensaio anterior. Como testemunhas e indicadores de virulência do isolado bacteriano, foram inoculadas plantas de tomate 'San Vito' (suscetível) e 'Guardião' (resistente). O desenho experimental foi inteiramente casualisado, com parcelas de um vaso com capacidade de $1,5 \mathrm{~L}$ contendo três plantas, em três repetições. A avaliação da doença foi realizada da mesma maneira indicada na avaliação de acessos de $S$. scuticum.

\section{Avaliação de acessos especiais de}

\section{S. stramonifolium}

Neste experimento, foram avaliados seis acessos de $S$. stramonifolium selecionados entre os acessos anteriormente avaliados, tomando-se como base a diversidade de origem geográfica de cada um (Tabelas 3 e 4). Estes acessos foram desafiados com três isolados de $R$. solanacearum de diferentes biovares e comprovadamente de alta virulência: RS 489 (R1Bv1), RS 488 (R1Bv2T) e RS 476 (R1Bv3). Da mesma forma que no ensaio anterior, como testemunhas e indicadores de virulência do isolado bacteriano, foram inoculadas plantas de tomate 'San Vito' (suscetível) e 'Guardião' (resistente), e berinjela (Solanum melongena) 'Ciça' (suscetível). O preparo de mudas, o preparo de inóculo, a inoculação, as condições pós-inoculação e a avaliação da doença foram realizados da mesma forma indicada na avaliação de acessos especiais de S. scuticum.

\section{RESULTADOS E DISCUSSÃO}

Para todos os ensaios, a murcha bacteriana se manifestou consistentemente nas testemunhas, indicando adequada combinação de isolados, concentração de inóculo, método de inoculação e ambiente favorável à doença.

\section{Solanum scuticum}

Foram observadas diferenças significativas de resistência entre os acessos avaliados. Quinze dos 26 acessos foram altamente resistentes, apresentando reação do tipo imunidade, pois nenhuma das plantas mostrou sintoma de murcha e a bactéria não foi visualizada pelo teste de exsudação em copo. Não foi observada clara relação entre a resistência e o local de coleta dos acessos. Por

Tabela 1. Acessos de Solanum scuticum avaliados para resistência à murcha bacteriana. Isolado RS476 de Ralstonia solanacearum (accessions of Solanum scuticum assessed for resistance to bacterial wilt). Brasília, Embrapa Hortaliças, 2014.

\begin{tabular}{llc}
\hline Acesso & Procedência & Plantas murchas (\%) \\
\hline CNPH 48 & Brasília-DF & $0,0 \mathrm{a}$ \\
CNPH 51 & Brasília-DF & $0,0 \mathrm{a}$ \\
CNPH 52 & Brasília-DF & $0,0 \mathrm{a}$ \\
CNPH 53 & Brasília-DF & $0,0 \mathrm{a}$ \\
CNPH 60 & Brasília-DF & $0,0 \mathrm{a}$ \\
CNPH 61 & Brasília-DF & $0,0 \mathrm{a}$ \\
CNPH 62* & Brasília-DF & $0,0 \mathrm{a}$ \\
CNPH 63 & Brasília-DF & $0,0 \mathrm{a}$ \\
CNPH 68 & Brasília-DF & $0,0 \mathrm{a}$ \\
CNPH 69* & Brasília-DF & $83,3 \mathrm{bc}$ \\
CNPH 70 & Brasília-DF & $100 \mathrm{c}$ \\
CNPH 72 & Formosa-GO & $100 \mathrm{c}$ \\
CNPH 73 & Brasília-DF & $0,0 \mathrm{a}$ \\
CNPH 74* & Brasília-DF & $100 \mathrm{c}$ \\
CNPH 76 & Brasília-DF & $0,0 \mathrm{a}$ \\
CNPH 77* & Brasília-DF & $0,0 \mathrm{a}$ \\
CNPH 78* & Assis Brasil-AC & $0,0 \mathrm{a}$ \\
CNPH 79 & Assis Brasil-AC & $0,0 \mathrm{a}$ \\
CNPH 80 & Cavalcante-GO & $1,7 \mathrm{a}$ \\
CNPH 82 & Cavalcante-GO & $83,3 \mathrm{bc}$ \\
CNPH 83 & Teresina de Goiás-GO & $33,3 \mathrm{~b}$ \\
CNPH 84 & Campos Belos-GO & $33,3 \mathrm{~b}$ \\
CNPH 85 & Campos Belos-GO & $33,3 \mathrm{~b}$ \\
CNPH 87* & Campos Belos-GO & $91,2 \mathrm{c}$ \\
CNPH 88 & Alto Paraiso-GO & $75,0 \mathrm{bc}$ \\
CNPH 89 & Alto Paraiso-GO & $91,2 \mathrm{c}$ \\
Tomate San Vito & Embrapa Hortaliças & 100,0 \\
Tomate Guardião & Takii & 58,3 \\
\hline
\end{tabular}

${ }^{1}$ plantas murchas (\%) em 12 mudas inoculadas, 12 dias após a inoculação (\% of wilted plants in 12 inoculated plants, 12 days after inoculation); $*$ Indica acessos escolhidos para o experimento seguinte (indicates accessions chosen for the following experiment). 
Tabela 2. Reação ${ }^{1}$ de acessos de Solanum scuticum, selecionados do primeiro experimento, a diferentes isolados de Ralstonia solanacearum (reaction ${ }^{1}$ of Solanum scuticum accessions selected in the previous experiment, to different isolates of Ralstonia solanacearum). Brasília, Embrapa Hortaliças, 2014.

\begin{tabular}{llll}
\hline \multirow{2}{*}{ Acesso } & \multicolumn{3}{c}{ Isolado de Ralstonia solanacearum } \\
\cline { 2 - 4 } & RS 476 & RS 488 & RS 489 \\
\hline CNPH 62 & $1,00 \mathrm{a}$ & $1,00 \mathrm{a}$ & $1,00 \mathrm{a}$ \\
CNPH 69 & $2,75 \mathrm{~b}$ & $2,50 \mathrm{~b}$ & $1,33 \mathrm{a}$ \\
CNPH 74 & $2,67 \mathrm{~b}$ & $3,42 \mathrm{~b}$ & $3,00 \mathrm{~b}$ \\
CNPH 77 & $1,00 \mathrm{a}$ & $1,00 \mathrm{a}$ & $1,00 \mathrm{a}$ \\
CNPH 78 & $1,00 \mathrm{a}$ & $1,00 \mathrm{a}$ & $1,00 \mathrm{a}$ \\
CNPH 87 & $2,25 \mathrm{~b}$ & $3,08 \mathrm{~b}$ & $2,75 \mathrm{~b}$ \\
Tomate San Vito & 4,00 & 4,00 & 4,00 \\
\hline
\end{tabular}

${ }^{1}$ Nota de 1 a 4 , sendo $1=$ planta sem sintoma; $2=$ uma folha até metade da planta murcha; $3=$ mais da metade até a planta toda murcha e 4= planta morta (disease scale from 1 to 4: $1=$ symptomless plant; $2=$ from one leaf to half plant wilted; $3=$ more than half to all plant wilted; $4=$ dead plant).

Tabela 3. Acessos de Solanum stramonifolium avaliados para resistência à murcha bacteriana. Isolado RS 476 de Ralstonia solanacearum (accessions of Solanum stramonifolium assessed for resistance to bacterial wilt). Brasília, Embrapa Hortaliças, 2014.

\begin{tabular}{|c|c|c|}
\hline Acesso & Procedência & $\begin{array}{c}\text { plantas murchas } \\
(\%)^{1}\end{array}$ \\
\hline CNPH 19* & Macapá-AP & 0 \\
\hline CNPH $20^{*}$ & Iranduba-AM I & 0 \\
\hline CNPH 21 & Iranduba-AM II & 0 \\
\hline CNPH 22 & Iranduba-AM III & 0 \\
\hline CNPH 23 & Manaus-AM & 0 \\
\hline CNPH 24 & Pres. Figueiredo-AM I & 0 \\
\hline CNPH 25 & Pres. Figueiredo-AM II & 0 \\
\hline CNPH 107 & Porto Acre-AC & 0 \\
\hline CNPH 108 & Porto Acre-AC & 0 \\
\hline CNPH 109 & Porto Acre-AC & 0 \\
\hline CNPH 110 & Porto Acre-AC, Vila V & 0 \\
\hline CNPH 111 & Porto Acre-AC, Vila V & 0 \\
\hline CNPH 112 & Rio Branco-AC & 0 \\
\hline CNPH 113 & Porto Acre-AC; Vila V & 0 \\
\hline CNPH 114 & Porto Acre-AC; Vila V & 0 \\
\hline CNPH 115 & Rio Branco-AC & 0 \\
\hline CNPH 116 & Rio Branco-AC & 0 \\
\hline CNPH 117 & Rio Branco-AC & 0 \\
\hline CNPH 118 & Rio Branco-AC & 0 \\
\hline CNPH 119* & Rio Branco-AC & 0 \\
\hline CNPH 120 & Pinheiro-MA 2 & 0 \\
\hline CNPH $121 *$ & Pinheiro-MA 1 & 0 \\
\hline CNPH $122 *$ & Mucajaí-RR & 0 \\
\hline CNPH 124 & Bujari-AC & 0 \\
\hline CNPH 336 & Cruzeiro do Sul-AC & 0 \\
\hline CNPH 349 & Alto Alegre-RR & 0 \\
\hline Tomate San Vito & Embrapa Hortaliças & 100,0 \\
\hline Tomate Guardião & Takii & 100,0 \\
\hline Berinjela Ciça & Embrapa Hortaliças & 88,9 \\
\hline
\end{tabular}

${ }^{1}$ plantas murchas (\%) em 12 mudas inoculadas, 12 dias após a inoculação (\% of wilted plants in 12 inoculated plants, 12 days after inoculation); *Indica acessos escolhidos para o experimento seguinte (indicates accessions chosen for the following experiment). exemplo, dos 15 acessos coletados em Brasília, 12 foram totalmente resistentes e 3 altamente suscetíveis (Tabela 1). Os dois isolados do Acre foram resistentes. Entretanto, o número de acessos foi insuficiente para fazer uma inferência mais segura sobre procedência do acesso e nível de resistência.

$\mathrm{Na}$ avaliação de acessos especiais de $S$. scuticum, comprovou-se a resistência dos acessos CNPH 62, CNPH 77 e CNPH 78 e a suscetibilidade dos acessos CNPH 69, CNPH 74 e CNPH 87 , reações que se mantiveram após inoculação com isolados virulentos de $R$. solanacearum de diferentes biovares. Embora tenha havido interação isolado $\mathrm{x}$ acesso, percebe-se que os acessos selecionados para este experimento possuem alto nível de resistência independentemente da biovar. Da mesma forma, a presença da bactéria nos vasos de plantas assintomáticas não foi detectada pelo teste de exsudação em copo. Isso credencia os referidos acessos no uso como porta-enxerto na busca de uma resistência estável à doença.

\section{Solanum stramonifolium}

Diferentemente do que foi observado para S. scuticum, quando se observou diferentes níveis de resistência entre acessos, todos os 26 acessos de S. stramonifolium foram resistentes quando inoculados com o isolado RS476 de $R$. solanacearum (Tabela 3). Essa resistência se manteve quando representantes de diferentes localidades dessa espécie foram inoculadas com três isolados altamente virulentos do patógeno (Tabela 4). A presença da bactéria não foi visualizada pelo teste de exsudação em copo. Esses resultados indicam que S. stramonifolium é uma das espécies da família Solanaceae com maior grau e estabilidade de resistência à murcha bacteriana, característica que pode ser explorada para fins de melhoramento genético em cruzamentos interespecíficos ou uso direto como porta-enxerto. Neste último caso, a dificuldade é que essa espécie possui espinhos, o que dificulta a operação de enxertia.

Em adição à característica de resistência à murcha bacteriana, em ensaio previamente conduzido em casa de vegetação, Mendonça et al. (2009b) observaram que a produtividade do 
Tabela 4. Reação ${ }^{1}$ de acessos de Solanum stramonifolium, selecionados do primeiro experimento, a diferentes isolados de Ralstonia solanacearum (reaction of Solanum stramonifolium accessions, selected in the previous experiment, to different isolates of Ralstonia solanacearum). Brasília, Embrapa Hortaliças, 2014.

\begin{tabular}{llll}
\hline \multirow{2}{*}{ Acesso } & \multicolumn{3}{c}{ Isolado de Ralstonia solanacearum } \\
\cline { 2 - 4 } & RS 476 & RS 488 & RS 489 \\
\hline CNPH 19 & $1,00 \mathrm{~ns}$ & $1,00 \mathrm{~ns}$ & $1,00 \mathrm{~ns}$ \\
CNPH 20 & 1,00 & 1,00 & 1,00 \\
CNPH 119 & 1,00 & 1,00 & 1,00 \\
CNPH 121 & 1,00 & 1,00 & 1,00 \\
CNPH 122 & 1,00 & 1,00 & 1,00 \\
Tomate San Vito & 4,00 & 4,00 & 4,00 \\
Tomate Guardião & 2,33 & 2,84 & 2,33 \\
\hline
\end{tabular}

${ }^{1}$ Nota de 1 a 4 , sendo 1= planta sem sintoma; 2 = uma folha até metade da planta murcha; $3=$ mais da metade até a planta toda murcha e 4= planta morta (disease scale from 1 to 4 : $1=$ symptomless plant; $2=$ from one leaf to half plant wilted; $3=$ more than half to all plant wilted; $4=$ dead plant)

híbrido de tomateiro longa vida 'Duradoro' enxertado no acesso CNPH 19 de S. stramonifolium não diferiu da produtividade obtida com 'Duradoro' enxertado no porta-enxerto de tomateiro 'Hawaii 7996' (padrão internacional de resistência à murcha bacteriana), e da produtividade obtida com 'Duradoro' não enxertado, comprovando boa compatibilidade deste acesso com o híbrido de tomateiro.

Foram identificados acessos de S. scuticum e $S$. stramonifolium com resistência múltipla à Ralstonia solanacearum e à Meloidogyne enterolobii; essa resistência qualifica essas espécies como de alto interesse para utilização como porta-enxerto em áreas com alta infestação com $R$. solanacearum (Rodrigues et al., 2012; Pinheiro et al., 2013). Ressalta-se, entretanto, que existe compatibilidade diferencial entre acessos de $S$. stramonifolium e de $S$. scuticum com cultivares de tomateiro; portanto, é necessário teste preliminar de compatibilidade.

\section{AGRADECIMENTOS}

Ao CNPq pela concessão de bolsa ao primeiro autor.

\section{REFERÊNCIAS}

GALLI, F. 1980. Manual de Fitopatologia: doenças das plantas cultivadas. São Paulo: Ceres. 515p.

KELMAN, A. 1954. The relationship of pathogenicity in Pseudomonas solanacearum to colony appearance on a tetrazolium medium. Phytopathology 44: 693-695.

LOPES, CA; BOITEUX, LS; ESCHEMBACK, V. 2015. Eficácia relativa de porta-enxertos comerciais de tomateiro no controle da murcha-bacteriana. Horticultura Brasileira 33: $125-130$.

MENDONÇA, JL; LOPES, CA; BOITEUX, LS; MOITA, AW; OLIVEIRA, AR. 2009a. Compatibilidade de enxertia de tomateiro e jurubeba (S. stramonifolium e $S$. asperolanatum). CONGRESSO BRASILEIRO DE TOMATE INDUSTRIAL, 3.; SEMINÁRIO NACIONAL DE TOMATE DE MESA, Goiânia. anais... Brasília, DF: Embrapa Hortaliças: Associação Brasileira de Horticultura; Goiânia; FAEG: UFG: Secretaria de Agricultura, Pecuária e Abastecimento: http://www.congressotomate.com.br/2010/ trabalhos-tomate.pdf

MENDONÇA, JL; ROSSATO, M; SILVA, BB; LOPES, C. 2009b. Resistência de jurubebas (Solanum spp.) a duas biovares de Ralstonia solanacearum. CONGRESSO BRASILEIRO DE FITOPALOGIA, 42., [anais...], 2009, Rio de Janeiro. http://www.congressofitopatologia. com.br/2010/trabalhos-tomate.pdf

PINHEIRO, JB; MENDONÇA, JL; SANTANA, JP. 2011. Wild Solanaceae: potential for the use as rootstocks resistant to root-knot nematode (Meloidogyne spp.). Acta Horticulturae 917: 243-247.

PINHEIRO, JB; RODRIGUES, CS; MENDONÇA, JL; PEREIRA, RB; CARVALHO, ADF. 2013. Reação de acessos de Solanum scuticum a Meloidogyne enterolobii. In: CONGRESSO BRASILEIRO DE NEMATOLOGIA 31, 2013, Cuiabá-MT: Sociedade Brasileira de Nematologia, 2013. p.79.

RODRIGUES, CS; PINHEIRO, JB; MENDONÇA, JL; CARVALHO, ADF; PEREIRA, RB. 2012. Reação de acessos de Solanum stramonifolium a Meloidogyne enterolobii. In: CONGRESSO BRASILEIRO DE FITOPATOLOGIA 45, agosto 2012, MANAUS-AM: Brazilian Phytopathological Society, 2012. p.42.

SANTOS, HS. 2003. Histórico da enxertia em hortaliças: utilização e pesquisa. In: GOTO, R; SANTOS, HS; CAÑIZARES, KAL (org). Enxertia em hortaliças. São Paulo: UNESP, p.11-14.

WICKER, E; GRASSART, L; CORANSONBEAUDU, R; MIAN, D; GUILBAUD, C; FEGAN, M; PRIOR, P. 2007. Ralstonia solanacearum strains from Martinique (French West Indies) exhibiting a new pathogenic potential. Applied and Environmental Microbiology 73: 6790-6801.

WINSTEAD, NN; KELMAN, A. 1952. Inoculation techniques for evaluating resistance to Pseudomonas solanacearum. Phytopathology 42: 628-634. 